\title{
Cold spray technology to promote conductivity of short carbon fiber reinforced polyether-ether-ketone (PEEK)
}

\author{
Patrizio Lomonaco ${ }^{1}$, Sebastien Weiller ${ }^{1}$, Imen Feki ${ }^{1}$, Antoine Debray ${ }^{1}$, \\ Francesco Delloro $^{1 *}$, Michel Jeandin ${ }^{1}$, Bernardo Favini ${ }^{2}$, Claude Rossignol ${ }^{3}$ \\ ${ }^{1}$ MINES ParisTech, MAT-Centre des Matériaux, 91003, Evry, France \\ ${ }^{2}$ Facoltà di Ingegneria Civile ed Industriale, University of Rome Sapienza, via Eudossiana 18, \\ 00189 - Rome, Italy \\ ${ }^{3}$ Lieberherr Aerospace, 408, avenue des Etats-Unis - B.P.2010 31016 Toulouse, France \\ 1patrizio.Iomonaco@mines-paristech.fr, ${ }^{1}$ sebastien.weiller@mines-paristech.fr, \\ 1imen.feki@mines-paristech.fr, ${ }^{1}$ antoine.debray@mines-paristech.fr, \\ $1^{*}$ francesco.delloro@mines-paristech.fr, \\ bernardo.favini@uniroma1.it, ${ }^{3}$ claude.rossignol@liebherr.com \\ ${ }^{1}$ michel.jeandin@mines-paristech.fr,
}

Keywords: Coldspray, composite, peek, copper, coating

\begin{abstract}
Recent studies showed that cold spray is a suitable way to produce metallic coatings on non-metallic surfaces such as polymers and composites for engineering applications. Mechanical bonding and particle anchoring process onto these substrates have not been totally understood yet. This study is focused on the creation of conductive coatings by cold spray onto short carbon fiber reinforced PEEK. For the requirements of the industrial application, the deposit should be able to tolerate both electrostatic and electric currents (higher than 10A). Because of their high conductivity, aluminium and copper powder seemed to be the best candidate materials. To promote adhesion and coating build up, copper-zinc and copper-PEEK mixed powders were also tested. A correlation between experimental and numerical tests has been adopted to assess and improve the possibilities of this material coupling. Both low pressure and high-pressure cold spray equipment were used for the spraying. Since polymer matrix-based composites are thermosensitive materials, it was necessary to develop a computational fluid-dynamics tool to investigate the interaction of the hot gas on the substrate and the correlation with the deposition process. A series of finite element simulations of single and multi-particle impacts onto local structures of the composite, as observed from SEM images of the specimens, is on-going. A classical pull-off test of the specimen will be adopted to collect data about coating adhesion strength. Finally, the four points measurement by Van der Pauw method will be used to assess the conductivity of specimens for different powders and coating thicknesses.
\end{abstract}

\section{Introduction}

Thermal spraying techniques are additive processes in which melted or solid powders are sprayed onto a surface. Cold spray (CS) is part of this family. In this process, particles are accelerated by a heated high pressure gas in a de Laval nozzle (convergent-divergent) towards a substrate. The main difference with other thermal spraying techniques is that particles maintain their solid state. This technology is industrially assessed only for metal powders and substrates. Recent studies began to involve other kinds of substrates. In 2006, Sturgeon et al. [1] realized for the first time an aluminum coating on short carbon fiber/PEEK (poly ether ether ketone) by cold spray. With an aluminum bond coat Zhou et al. [2] in 2011, still using short carbon fibers/PEEK composite substrates, succeeded in spraying copper coatings. In 2014, Che and Yue [3] used the cold spray to coat a continuous carbon fiber/epoxy composite with aluminum, copper and tin. They obtain a coating only with tin. Other authors only focused on non-reinforced polymer substrates, with good results 
[4-5]. In 2016 a study of Bortolussi [6] explored successfully the possibility to have a proper and conductive coating onto PEEK reinforced with continuous carbon fibers by means of a mixture of copper and PEEK powder.

The intent of this study is to extend CS to dissimilar material couples, in particular metal onto composite substrates, for the achievement of multi-material and multi-features assemblies. The scientific objective of this work is to understand the mechanisms underlying the coating build-up onto composite substrates and their quality in terms of electrical conductivity. Because of the fibrous, brittle and thermosensitive nature of the substrate, impact conditions must be optimized and phenomena at micro and macro scale should be analyzed to understand particle impact, anchoring and coating build up process. A modeling approach, going from the micro to the macro scale, is a precious tool to address effectively the problem of cold spray deposition onto a complex material, as the composite proposed in this study

\section{Materials and Methods}

The powders used in this work were commercial-purity aluminium (irregular shape), copper (spherical shape), PEEK (irregular shape), zinc (spherical shape), with average particle sizes of 45, 65, 17 and $20 \mu \mathrm{m}$, respectively. The substrates consisted in plates made of $40 \%$ (vol) carbon fibre reinforced PEEK. They were cut in samples of $25 \times 25 \times 2 \mathrm{~mm}^{3}$ before being sprayed.

A Low-pressure cold spray (LPCS) system was used,

The LPCS system was a Dymet 523 from Dycomet (Akkrum, The Netherlands), equipped with compressed air as principal gas. With respect to the high pressure systems, LPCS provided a downstream injection of the particles (i.e. after the nozzle throat), decreasing the risk of clogging inside the throat, in addiction to that it makes possible to spray at lower pressure and high temperature, making sprayed particle softer and less erosive for the substrates.. Several spraying parameters were tested, in different ranges depending on the material, as presented in Table 1.

Table1: low pressure cold spray parameters

\begin{tabular}{|l|l|l|l|l|} 
Powder & $\begin{array}{l}\text { Gas } \\
\text { Temperature } \\
{\left[{ }^{\circ} \mathrm{C}\right]}\end{array}$ & $\begin{array}{l}\text { Gas } \\
\text { Pressure } \\
{[\mathrm{MPa}]}\end{array}$ & $\begin{array}{l}\text { Stand-off } \\
\text { distance } \\
{[\mathrm{mm}]}\end{array}$ & $\begin{array}{l}\text { Transverse Speed } \\
{[\mathrm{mm} / \mathrm{s}]}\end{array}$ \\
\hline Aluminum & 400 to 600 & 0.4 & 10 & 100 \\
\hline Copper & 350 to 600 & 0.4 & 10 & 100 \\
\hline Copper/Zinc & 400 & 0.4 & 10 & 100 \\
Copper/PEEK & $300-500$ & 0.4 & $10-20$ & 100 \\
\hline
\end{tabular}

Specimens were characterized with a ZEISS DSM982 Gemini SEM and a LEICA DMI 5000 optical microscope equipped with a camera.

\section{Results and discussion}

LPCS technique extends the possibility to achieve a proper deposition onto sensitive substrates, as polymerbased composites, and in any case where substrate erosion is a limiting factor for the coating build up. Results will be presented for each feedstock powder material tested.

In some applications where the weight is an important issue, the product of resistivity and density is more important than absolute low resistivity. The lower this product the better the performance. 
Table 2: density and conductivity of metal powders

\begin{tabular}{|l|l|l|l|}
\hline Powder & Density & $\begin{array}{l}\text { Resistivity at } \\
20^{\circ} \mathrm{C} \\
{[\mathrm{Ohm} \cdot \mathrm{m}]}\end{array}$ & $\begin{array}{l}\text { Resistivity } \mathrm{x} \text { density product } \\
{\left[\mathrm{Kg} \cdot \mathrm{Ohm} / \mathrm{m}^{2}\right]}\end{array}$ \\
\hline Aluminum & 2810 & $2.65 \times 10^{-8}$ & $0.74 \times 10^{-4}$ \\
Copper & 8960 & $1.68 \times 10^{-8}$ & $1.50 \times 10^{-4}$ \\
\hline Zinc & 7135 & $5.90 \times 10^{-8}$ & $4.20 \times 10^{-4}$ \\
\hline
\end{tabular}

Aluminum: Deposition started for temperatures above $500^{\circ} \mathrm{C}$. Despite the downstream injection, the high temperature and the long term storage of the powders, caused frequent nozzle clogging and a proper coating was realized for only one set of cold spray parameters.

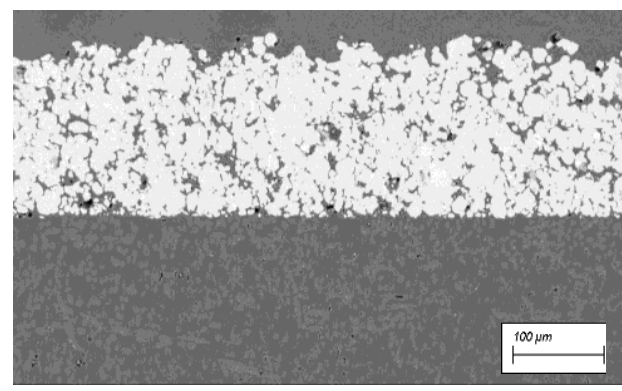

Fig 1: SEM (Secondary electron sensor) cross section of LPCS of aluminum powder onto PEEK composite substrate

The only coating obtained, as showed in Fig. 1, resulted to be porous. Further experiments will be necessary to make a quantitative analysis for aluminium deposition onto PEEK, using this time fresh powders.

Copper: Particles revealed to be too hard to be sprayed directly onto a PEEK substrate. In Fig. 2 is clearly visible that only few particles adhered on the surface, some fibers resulted to be broken and there were traces of erosion. The increase of the gas temperature up to $700^{\circ} \mathrm{C}$, in order to soften copper particles, resulted in a damaging of the PEEK surface, as shown in Fig. 3.
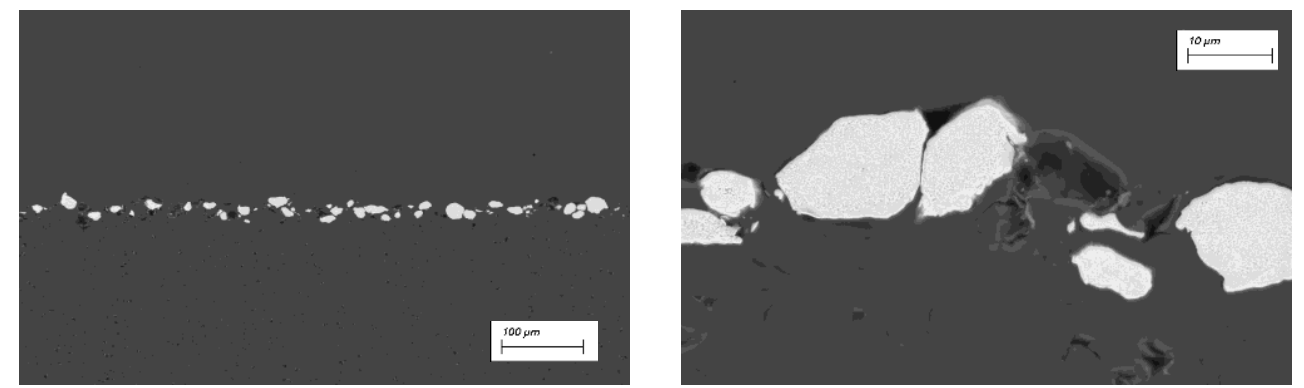

Fig 2: On the left, SEM (BSD sensor) cross section of copper sprayed onto a PEEK composite substrate by LPCS; on the right, a detail of copper particles at higher magnification. 


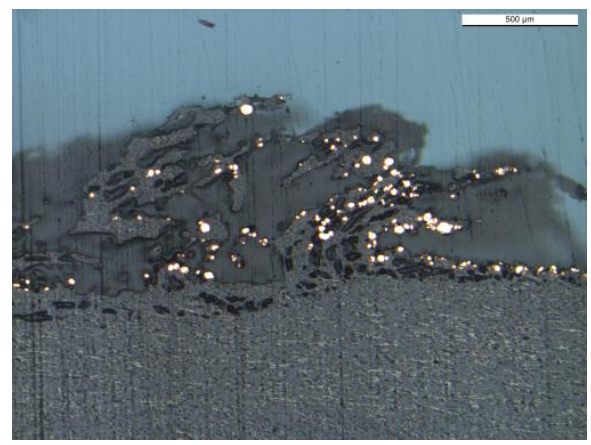

Fig 3: Optical cross section of a damaged PEEK composite substrate.

Mixture of copper (80\% vol) and PEEK (20\% vol) : as reported in [6], polymer/metal powder mixing was find to be a good way to make possible the deposition onto polymer base composite substrates. Three different temperature and two different stand-off distance were tested. Results are shown in Fig. 4.
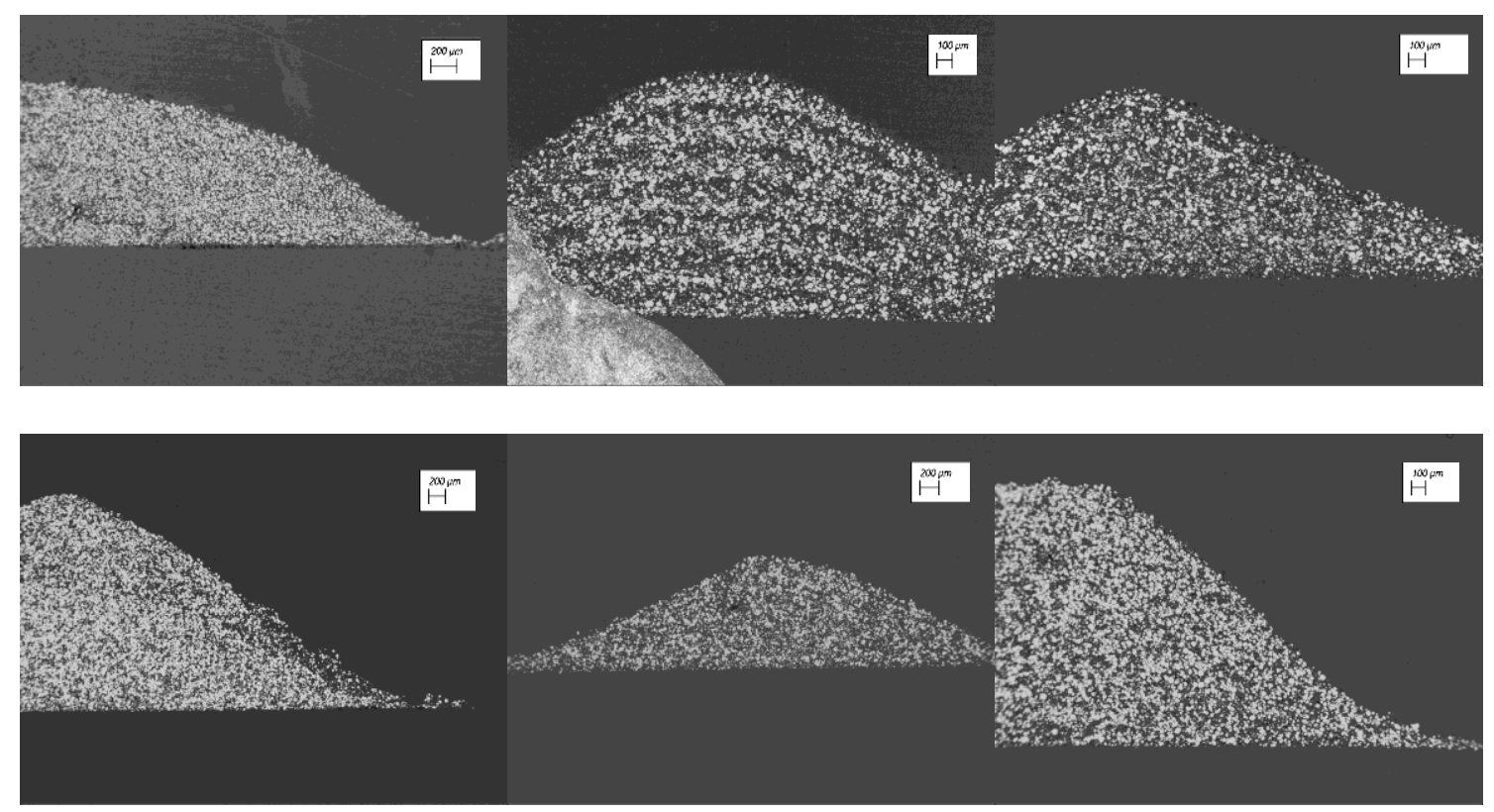

Fig 4: SEM (BSD) cross section of LPCS of copper-PEEK powder mixture onto PEEK composite substrate. The three images on the top refers to tests at a fixed stand-off distance of $10 \mathrm{~mm}$, for three different temperatures (from left to right A,B,C samples, respectively, 300, 400 and $500^{\circ} C$ ) and five passes. On the bottom, the stand of distance was increased to $20 \mathrm{~mm}$ (samples F,E,D) with the same conditions of temperature.

By means of image analysis tool, a quantitative estimation of the copper-peek mixture ratio after deposition was performed. Results listed in table 3 shown that unless the initial copper volume content was $80 \%$ in the mixture, after the deposition process this value dropped below $60 \%$ vol.

One can also notice that the higher the temperature the higher the copper content.

Table 3: Cold spray parameters and copper content of the sprayed samples

\begin{tabular}{|l|l|l|l|l|}
\hline Sample & $\begin{array}{l}\text { Gas } \\
\text { Pressure } \\
{[\mathrm{MPa}]}\end{array}$ & $\begin{array}{l}\text { Gas } \\
\text { Temperature } \\
{\left[{ }^{\circ} \mathrm{C}\right]}\end{array}$ & $\begin{array}{l}\text { Stand-off } \\
\text { distance } \\
{[\mathrm{mm}]}\end{array}$ & $\begin{array}{l}\text { Copper content } \\
{[\% \text { vol }]}\end{array}$ \\
$\mathrm{A}$ & 0.4 & 300 & 10 & 37 \\
\hline
\end{tabular}




\begin{tabular}{|l|l|l|l|l|}
\hline B & 0.4 & 400 & 10 & 39 \\
\hline C & 0.4 & 500 & 10 & 66 \\
\hline D & 0.4 & 500 & 20 & 49 \\
\hline E & 0.4 & 400 & 20 & 41 \\
F & 0.4 & 300 & 20 & 43 \\
\hline
\end{tabular}

A closer look on the interface of these specimens shows that the mechanism of coating formation is not the usual one for the cold spray of metal onto metal. One can distinguish three phases in this deposit [Fig.5], the first is composed by copper particles that resulted to be not deformed. The second composed by highly deformed PEEK particles acting as a bonding matrix. The black holes are due to the debonding of copper particles after polishing.

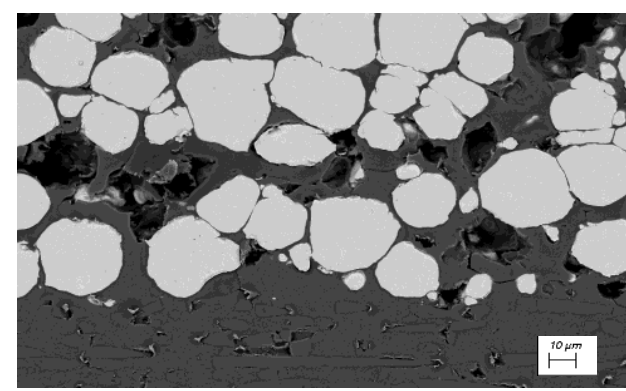

Fig 5: SEM cross section of LPCS of copper-PEEK powder mixture onto PEEK composite substrate, closer look.

Mixture of copper $(50 \% \mathrm{w})$ and zinc $(50 \% \mathrm{w})$ : The zinc content allowed to avoid erosion of the substrate and to create a coating $2 \mathrm{~mm}$ thick as shown in the Fig. 6

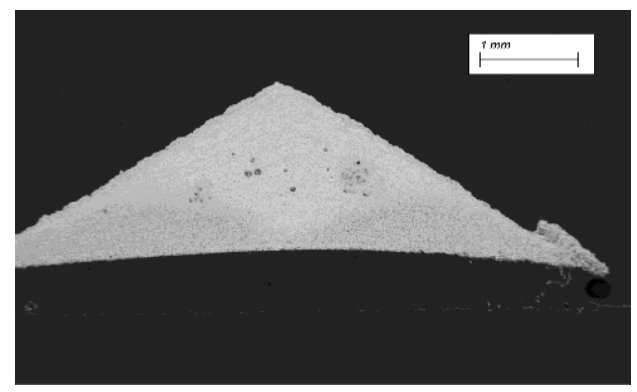

Fig 6: SEM cross section of LPCS of copper-zinc powder mixture onto PEEK composite substrat

Unfortunately, the coating detached completely from the substrate. This seems to be related to thermal stress, the linear thermal expansion coefficient between the metal coating and the composite substrate differs significantly. While this coefficient varies in the range $15-30\left(10^{-6} 1 / \mathrm{K}\right)$ for the metals in a PEEK composite can reach $80-90\left(10^{-6} 1 / \mathrm{K}\right)$.

Conclusions. The cold spray technology feasibility for metal spraying onto short carbon fiber reinforced PEEK was assessed. Aluminium powder, copper-PEEK and copper-zinc mixture powders were successfully deposited onto a short carbon fibre reinforced PEEK substrate. Particle adhesion and coating build-up process seemed to follow different behavior with respect to the classical metal onto metal case and need to be further investigated.

Metal-polymer mixture is a promising way to reduce substrate erosion and promote deposition onto polymers and composites. 
Outlook. More observation, testing and analysis will be performed to characterize mechanical and electrical features of the metal coatings. A minimum thickness (for each metal), to match the requirements in terms of electrical resistivity, will be assessed.

A four-points Van der Pauw method [7] will be used for the experimental measurements and an adhesion test has been envisaged for mechanical assessment.

Percolation of metal powder in the PEEK-copper mixture and then morphological features of this coating will be assessed by experimental and numerical test.

The computational fluid-dynamics tool (on going) will be helpful to check the temperature of gases and particles impacting the composite surface.

Acknowledgments. Special thanks to Ferdy Touwen and Klaas Rozema of Dycomet Europe for LPCS tests at Dycomet HQ. The authors are grateful to DGA (French Army General Direction) for the financial support.

\section{References}

[1] Sturgeon, A., B. Dunn, S. Celotto, and W. O'Neill: Cold Sprayed Coatings for Polymer Composite Substrate. ESA SP, 616 (2006).

[2] Zhou, X. L., A. F. Chen, J. C. Liu, X. K. Wu, and J. S. Zhang: Preparation of metallic coatings on polymer matrix composites by cold spray. Surface and Coatings Technology 206, no. 1 (2011): 132-136.

[3] Che, H. Q., and S. Yue: Cold Spray of Carbon Fiber Reinforced Polymer for Lightning Strike Protection. International Thermal Spray Conference. Barcelona: DVS, (2014).

[4] Lupoi, R., and W. O'Neill: Deposition of metallic coatings on polymer surfaces using cold spray. Surface and Coatings Technology 7, no. 205 (2010): 2167-2173.

[5] Giraud, D., F. Borit, V. Guipont, M. Jeandin, and J. M. Malhaire: Metallization of a Polymer using Cold Spray: Application to Aluminum Coating of Polyamide66.International Thermal Spray Conference. DVS, (2012).

[6] Vincent Bortolussi, François Borit, Anthony Chesnaud, Michel Jeandin, Matthieu Faessel, et al.. Cold spray of metal-polymer composite coatings onto carbon fiber-reinforced polymer (CFRP). 7 p., 2016, ITSC 2016 - International Thermal Spray Conference.

[7] L. Van der Pauw. A method of measuring specific resistivity and Hall effect of discs of arbitrary shape. Philips Res. Rep. 13 (1958), p. 1-9. 